\title{
Research on Transnational Athletics Coverage and Cultural Bias
}

\author{
Yuexi $\mathrm{Su}^{1 *}$ \\ ${ }^{1}$ Ramona Convent Secondary School, Alhambra, California, 91803, United States \\ *Corresponding author. Email: ysu.22@ramonaconvent.org
}

\begin{abstract}
Under current day media circumference, the transnational athletics coverage and cultural prejudice that are manipulated exacerbate hatred. To find out the causes, the researcher chose a few mainstream media from varied countries and did a quantitative content analysis based on the discoveries. As in the process of researching, the researcher discovered various causes that contribute to the hostility, including collective cultural unconsciousness, news media bias and coverage, and audiences' lean-to-one side opinion climate. The study is according to detailed analysis and evaluation of Sun Yang's Drug Cheat. Through this research, people can avoid control of minds, critical thinking, and various articles from different perspectives. Conclusively, the researcher uncovered numerous variables that lead to the antagonism, including collective cultural consciousness, news media bias and coverage, and audiences' lean-to-one side opinion climate.
\end{abstract}

Keywords: athletes, agenda-setting, journalism, collective unconsciousness, opinion climate

\section{INTRODUCTION}

Sun Yang, a three-time Olympic swimming champion from China, was barred from competition for eight years by the Court of Arbitration for Sport on February 28, 2020. This incident started on the evening of September 4, 2018, when three staff members of the International Doping Control Management Company conducted an out-of-competition doping inspection on Sun Yang. Sun declined to take the test during the process because he was skeptical of its validity and accuracy. Sun Yang's case has become a mystery due to the missing blood and urine samples. As a result, nobody knows if Sun Yang took the drug during the Olympics. Comparing Chinese mainstream media such as Weibo, Tencent news, Tik Tok (Chinese region), Xinhua news, bilibili, to the English-speaking countries, such as $\mathrm{CNN}, \mathrm{ABC}$, The Sunday Times, the reportings from both sides were holding an opposing point of view against each other. To determine the causes, the researcher selected a few mainstream media outlets from various nations and conducted a quantitative content analysis based on the findings. According to a rigorous examination and evaluation of Sun Yang's Drug Cheat, the researcher uncovered numerous variables that lead to the antagonism, including cultural collective unconsciousness, news media bias and coverage, and audiences' lean-to-one side opinion atmosphere. It is hoped that through this paper, people can avoid losing control of their minds, develop critical thinking skills, and read a range of articles from various perspectives.

Since the 1950s, mass media such as cinema, radio, and television have played a key role in political power as the industrial revolution rise. Mass media is the source of records and information together with newspapers, magazines, radio, and television, which attain and impact vast people. The traits include having many audiences and being controlled by a specific device (such as TV, radio, website, etc.) and using a particular technology to spread the information. [25] The present-day prevalent mass media includes television, radio, paper print, and Internet. However, a lack of focus on specific topics is a common criticism of mass media. Mass news media have to choose to broadcast news from one particular topic and ignore some critical information or report them with a bias to meet the needs of a broader readership.

Sun Yang, a three-time Olympic swimming champion and six-time Olympic medalist from China, was barred from competition for eight years by the Court of Arbitration for Sport on February 28, 2020, for a drug-testing violation, which will keep him out of the 
Tokyo Olympics this year and potentially end his career. He declined to meet with three anti-doping officials who came to his home to collect blood and urine samples in China. The incident started on the evening of September 4, 2018, when three staff members of the International Doping Control Management Company (IDTM) conducted an out-of-competition doping inspection on Sun Yang. Sun declined to take the test during the process because he was skeptical of its validity and accuracy. When his claim was denied, his mother had a security guard break his blood-sample vials with a hammer. Sun failed to send a urine sample as a result. As a result, sun Yang "violently refuses to take the exam," according to IDTM's submission to FINA (International Swimming Federation).

On November 19, 2018, FINA held a hearing in Lausanne, Switzerland, to discuss the matter. Then, on January 3, 2019, FINA said that Sun had not broken any anti-doping rules. Since it was unhappy with the decision, the World Anti-Doping Agency lodged an appeal with the Court of Arbitration for Sport on March 12, 2019. The Court of Arbitration for Sport (CAS) held a public hearing on the case on November 15, 2019, in Montreux, Switzerland, a broadcast live on the Internet worldwide. The trial went on for 12 hours. The World Anti-Doping Agency (WADA) decided against Chinese swimmer the Court of Arbitration announced Sun Yang and the governing body FINA for Sport (CAS) on February 28, 2020. Sun Yang will be barred from competing for the next eight years. On April 1, 2021, the Court of Arbitration for Sport (CAS) announced that the retrial hearing of Sun Yang's case would be held online in May 2021.

The Sun Yang case has become a mystery due to the missing blood and urine samples. Nobody knows if Sun Yang took the drug during the Olympics. At the same time, there have been fierce controversies. They compare Chinese mainstream media such as Weibo, Tencent news, tik tok (Chinese region), Xinhua news, bilibili, etc., to English-speaking countries, such as CNN, ABC, The Sunday Times. The reportings from China and English-speaking countries held an opposing point of view against each other. Chinese people's opinion on the Sun Yang case is also quite distinct from English Speaker's side. The Chinese hand is on Sun Yang's side and feels that he has been handled unfairly. However, English-speaking countries such as the United States, the United Kingdom, and Australia were more likely to believe Sun Yang cheated in the Olympic games, perfectly fitting the News' opinion in their respective countries.

\section{PROBLEMS OF MASS MEDIA IN SPORTS NEWS REPORTING}

\subsection{Public stereotype}

One cause of the anger between people is the cultural theories, which influence the public, shaping public recognition. People always form specific subconsciousness as they are submerged in their own culture or social background due to the knowledge they have received since they were born. People of similar backgrounds unintentionally think, imagine, and make decisions in the same way. Even if they did not intend to slander or defend, the cultural aspect significantly impacted people's reactions to a case.

As a closer investigation from English-speaking countries such as the U.S., Britain, Canada, and Australia in terms of their perspectives, there is certain rationality for English journalists to think of Sun Yang as the cheater. First, there was a stimulant scandal in the past on Chinese swimmers. In early October, Japanese drug testers who took urine samples at the Asian Games in Hiroshima revealed that 11 Chinese athletes tested positive for drugs, including seven top Chinese swimmers, three women, and four men. [15] This scandal leads to the rise of suspicion while Chinese athletes win an achievement. Similarly, Ye Shiwen, the gold medal winner in London's Olympic games in, 2012 also receives mistrust from western media. Second, from a physical body structure perspective, there is a stereotype that Asian athletes are usually shorter, weaker, and swim slower compared to other races. Except for Japan and South Korea, Asian countries never won a swimming medalist in Olympics until 2012, Sun Yang won. The list of medalists was full of American and Australian athletes, which makes it relatively absurd for people to see Chinese medalists who beat all of the previous champions who appear on the list. Furthermore, the drug cheating case explains the unexpected championship. Finally, Australia was irritated by Sun Yang's disrespectful remarks after the Olympic games. The inclination of news media in English-speaking countries is shaped by all of these prejudices that come from their context.

In the same way, there are a lot of stereotypes in China. For example, Sun Yang has a considerable fan base and is well-known. His commitment to his preparation can be seen in several films, variety shows, and interviews. Furthermore, all Chinese athletes were professionals, and China is responsible for their taxes, which means that in many Chinese minds, the championship on sports represents the country's power. As a result, the Chinese developed an intense patriotism for the athletes and sports. Athletes who win medals for China are always referred to as "heroes." As a result, it was difficult for the Chinese to admit that their hero was a cheater. 


\subsection{Cultural bias}

In addition, when the media clarify their position on an event, the readers stand an excellent chance to follow and agree with the report. In the book Teaching of communication, the author points out that "For ordinary people with limited physical horizons and activities, this knowledge and judgment of current events and their importance usually come from the mass media, which are important sources not only of information but also of influence." []Therefore, the agenda-setting theory, which is one method used by the media to influence people's opinions, also played an important role.

According to The Agenda-Setting Function of Mass Media, the Agenda theory's description is "the mass media set the agenda for each political campaign, influencing the salience of attitudes toward the political issues." [21]. In this theory, mass communication can often determine people's specific views on an event or opinion. However, it can effectively influence the facts and opinions people pay attention to and the order in which they talk by providing information and arranging relevant issues. One of the typical methods that existed in the practice of Agenda-setting is the 0/1 effect. The $0 / 1$ impact is when the media report or do not report a specific fact and influence the event's public perception.
From "perception" to "emphasis" to "prioritization" of a series of issues according to their importance, it is a process of cumulative influence and effect, and the further the product becomes more prominent and more profound.

According to the investigation on 11 news media reports, Chinese media tends to write about the positive side of Sun Yang, such as Sun Yang's hard work during training. From a report in Tencent News, the writer talks about Sun Yang's heart disease caused by overloaded high-intensity training and explains that Sun Yang's drug cheat case in 2014 was an accident caused by the heart medicine taken by mistake. On Weibo, Sun Yang had a post on February 28, 2020. He emphasized that the inspectors are not qualified, which prompted Chinese media to underscore the unprofessionalism of the drug tester from DCA. According to the China Daily's report. "DCA in Sun Yang Case Was' Construction Worker'.", [9]that is one of the testers who used to work as a construction worker. Moreover, in the Chinese media included in the table below, every media clarifies that Sun's mother called a person and broke the test sample. In contrast, except NPR and New York Times, all English media blurred this fact (detail sees table 1).

Table 1 Chinese and Western media report on the incident of Sun Yang

\begin{tabular}{|c|c|c|c|c|c|c|c|c|c|c|c|}
\hline & $\begin{array}{l}\text { Sun Yanga } \\
\text { Hardworkeng }\end{array}$ & $\begin{array}{l}\text { The } \\
\text { break } \\
\text { of the } \\
\text { urine } \\
\text { tant } \\
\text { samph }\end{array}$ & $\begin{array}{l}\text { The } \\
\text { reason } \\
\text { for Sun } \\
\text { Yangs } \\
\text { anger }\end{array}$ & $\begin{array}{l}\text { Suapracus } \\
\text { on drug } \\
\text { tester }\end{array}$ & $\begin{array}{l}\text { Suspouous } \\
\text { on Sun } \\
\text { Yang's act }\end{array}$ & $\begin{array}{l}\text { Sun } \\
\text { Ysong's } \\
\text { compettor } \\
\text { Harton }\end{array}$ & $\begin{array}{l}\text { Son } \\
\text { Yengs } \\
\text { mother } \\
\text { and } \\
\text { Coads. }\end{array}$ & $\begin{array}{l}\text { WADA } \\
\text { Rad } \\
\text { Cais's } \\
\text { attifude }\end{array}$ & $\begin{array}{l}\text { Sun Yanga } \\
\text { backgound } \\
\text { (Negative) }\end{array}$ & $\begin{array}{l}\text { Sum Yangs } \\
\text { backgound } \\
\text { (pasttive) }\end{array}$ & $\begin{array}{l}\text { Chru's } \\
\text { exhlarant } \\
\text { history }\end{array}$ \\
\hline $\begin{array}{l}\text { The Naw } \\
\text { York Times }\end{array}$ & & $\sqrt{2}$ & $\sqrt{ }$ & & $\sqrt{ }$ & & $\sqrt{ }$ & $\sqrt{ }$ & & & $\sqrt{ }$ \\
\hline CEC & & $\sqrt{1}$ & & & & & & & $\sqrt{7}$ & & \\
\hline$\overline{A B C}$ & & $\sqrt{ }$ & & & & $\sqrt{1}$ & & & $\sqrt{1}$ & & \\
\hline $\begin{array}{l}\text { Global } \\
\text { Times }\end{array}$ & $\sqrt{ }$ & & & & & & & & & $\sqrt{ }$ & \\
\hline Chima Daly & & & & $\sqrt{ }$ & & & $\sqrt{ }$ & & & $\sqrt{ }$ & \\
\hline Poople.com & $\sqrt{ }$ & $\sqrt{2}$ & $\sqrt{2}$ & $\sqrt{1}$ & & & & & & $\sqrt{1}$ & \\
\hline NPR & $\sqrt{1}$ & $\sqrt{ }$ & $\sqrt{ }$ & & & & $\sqrt{ }$ & $\sqrt{ }$ & & $\sqrt{ }$ & $\sqrt{ }$ \\
\hline $\begin{array}{l}\text { Sydnay } \\
\text { Moming } \\
\text { Harald }\end{array}$ & & $\sqrt{2}$ & & & $\sqrt{ }$ & $\sqrt{ }$ & & $\sqrt{ }$ & $\sqrt{ }$ & & \\
\hline Farad Sun & & $\sqrt{ }$ & $\sqrt{ }$ & & $\sqrt{ }$ & $\sqrt{2}$ & & $y$ & $\sqrt{7}$ & & \\
\hline Sina Sponts & y & $\sqrt{ }$ & & $\sqrt{ }$ & & $\sqrt{ }$ & $\sqrt{ }$ & & & $\sqrt{ }$ & \\
\hline BEC & & $\sqrt{ }$ & & & $\sqrt{ }$ & $\sqrt{1}$ & & $\sqrt{ }$ & $\sqrt{ }$ & & \\
\hline
\end{tabular}

Instead, the English media's topic choice mainly focuses on Sun Yang's exhilarating history in 2014 and his rude act towards his competitor Aussie Norton. For example, the Herald Sun used over half of the video to report on Horton's question about Sun Yang's eligibility, and Sun Yang's rude, humiliating words to Horton, such as "You are a loser, and I win" as well as Horton's judgment of Sun Yang as a "cheater." In the report of Sun Yang's drug case that happened in 2019, many of the media choose to include Nordon's negative comment as part of Sun Yang's case's description even though Nordon was a bystander. In addition, many English media refuse to talk about Sun Yang's feedback on doping and why he was losing his temper while doing the test.

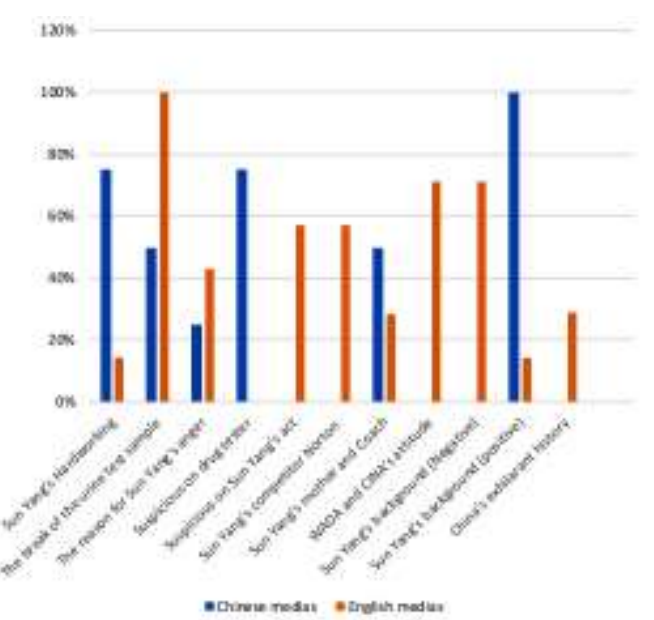

Figure 1 the bar chart based on the data of Table 1 
The different choices on the facts as journalists include in their reports contribute to a perfect agenda setting. For example, when reading Chinese news, readers are more likely to come across existing terms like "unfair," "unprofessional," and "misunderstanding," and believe that Sun Yang is innocent. In contrast, they were told that Sun was most likely taking exhilarant because of his past cheating when reading English news.

\subsection{Collective unconsciousness}

Leaning to one side's opinion about Sun Yang's case builds a perfect opinion climate. Under such circumstances, the aggression becomes much easier to raise, or in other words, the opinion climate establishes a group polarization. In the book CROWD: a Study of the Popular Mind, the writer Bon Gustave Le states that "by the mere fact that he forms part of an organized crowd, a man descends several rungs in the ladder of civilization. Isolated, he may be a cultivated individual; in a crowd, he is a barbarian - that is, a creature acting by instinct. He possesses the spontaneity, violence, ferocity, enthusiasm, and heroism of primitive beings, whom he further tends to resemble by the facility with which he allows himself to be impressed by words and images [11]. In the Sun Yang case, this also happened. The Sydney Morning Herald reported this phenomenon: "Sun's fans reacted with fury at the news of his eight-year suspension. Social media platforms were flooded with messages of support for the swimmer and anger at the decision, which many described as anti-Chinese and designed to harm the country." China also says Australia is on "The Fringes of Civilization" following the Olympic drug dispute. Simultaneously, as the media repeatedly inform the audience that Aussie Norton expressed his public disdain for Sun, the anger also arises around Norton's fans and many English readers. The radical words used by the media, for example, the Heral Sun, describe Sun as a "guilty swimmer" who deserves the "penalty" of eight-year doping. The tones and use of words can also infuriate the public. Norton and the media also sparked a verbal spat on the Internet. "I had no time or respect for drug cheats", said Norton, according to the BBC.[16]

\section{DISCUSSION}

The Conflicts between fans never ends. Recently, a new hearing will take place during the week of May 24-28, 2021, according to the CAS. The Swiss Federal Supreme Court has clarified why it ordered a retrial in Olympic swimming champion Sun Yang's doping case, alleging anti-China prejudice by one of the judges involved in the case. Some think this is a ludicrous excuse, whereas others believe it is fair. In the Sun Yang case is hard to conclude which side is correct ever since the blood and urine samples were destroyed. But what people can still complete is to look at the news reports they never get in touch with to search for the truth in their minds. Thus, people can avoid control of mind, have the critical thinking, and read various articles from different perspectives.

\section{CONCLUSION}

According to a rigorous examination and evaluation of Sun Yang's Drug Cheat, the researcher uncovered numerous variables that lead to the antagonism, including cultural collective unconsciousness, news media bias and coverage, and audiences' lean-to-one side opinion climate. However, this study still has some shortcomings, such as insufficient content quantitively data collection. In addition, further analysis is needed for the causes. What is more, to solve this problem, the researchers should focus on the audience itself. For example, a feasible and effective way is to increase audiences' media literacy. Media literacy is the method that enables people to access, critically assess, create, or influence. Educators, in particular, should concentrate their efforts on developing adequate media literacy among the younger generation. As a result, with critical thinking, it was difficult to mold people into what others wanted them to be. Such improvement not only helps people to be more rational while browsing online but also mitigates international relationships.

\section{ACKNOWLEDGMENT}

I am eternally grateful to my AP Capstone teacher, Dr. Vincent, who guides me through the research. He taught me how to find a topic, research online, and form a formal essay. I cannot write this paper without him. I also genuinely appreciate my mother, Guo Liu, for giving me a professional suggestion on researching and sharing her database with me. I also thank them for her patience and support. Lastly, I want to thank my classmates in the AP Capstone class who help me brainstorm topics during my seminar class.

\section{REFERENCES}

[1] Mather, Victor, et al. "Sun Yang, Chinese Olympic Swimmer, Gets 8-Year Doping Ban." The New York Times, The New York Times, February 28 2020,

www.nytimes.com/2020/02/28/sports/olympics/su n-yang-doping-ban.html.

[2] Dai Yan . "FINA Silent on Sun Furor." Chinadaily.com.cn, www.chinadaily.com.cn/a/201901/30/WS5c51010 4a3106c65c34e740b.html.

[3] "Sun Yang attends court of Arbitration for Sport hearing in Switzerland." Sun Yang attends court of 
Arbitration for Sport hearing in Switzerland _ Photo channel _ Xinhua, www.xinhuanet.com/photo/2019-11/16/c_1125239 443_3.htm.

[4] Dag, O. George Orwell: The Sporting Spirit, www.orwell.ru/library/articles/spirit/english/e_spir it.

[5] "Chinese Swimmer Sun Yang Granted Public Trial for Doping Hearing | CBC Sports." CBCnews, CBC/Radio Canada, 20 Aug. 2019, www.cbc.ca/sports/olympics/summer/aquatics/worldaquatics-sun-yang-public-trial-doping-1.5253283.

[6] Hinds, Richard. "Mack Horton's Protest Shows Why Athletes Feel Abandoned in Anti-Doping Fight." ABC News, ABC News, July 252019 , www.abc.net.au/news/2019-07-26/mack-horton-su n-yang-protest-shows-anti-doping-frustration/1134 7100.

[7] ABC News. "Swim Champ Horton Takes Another Doping Swipe at China's Sun Yang." ABC News, ABC News, July $21 \quad 2017$, www.abc.net.au/news/2017-07-22/mack-horton-ta kes-another-swipe-at-sun-yang/8733954.

[8] Times, Global. "China's Swimming Body Believes in Sun Yang's Innocence." Global Times, www.globaltimes.cn/content/893566.shtml.

[9] Guan Xiaomeng . "DCA in Sun Yang Case Was' Construction Worker'." Chinadaily.com.cn, www.chinadaily.com.cn/a/201911/19/WS5dd3936 9a310cf3e355786f0.html\#: :text=HANGZHOU\% 20-\%20One $\% 20$ of\%20the \%20three, $\% 2 \mathrm{C} \% 20$ but $\% 20 \mathrm{a} \% 20$ construction $\% 20$ worker.

[10] Young, Kevin, and Michael D. Smith. "Mass Media Treatment of Violence in Sports and Its Effects." Current Psychology, vol. 7, no. 4, 1988, pp. 298-311., doi:10.1007/bf02686627.

[11] BON, GUSTAVE LE. CROWD: a Study of the Popular Mind. DIGIREADS COM, 2019.

[12] McCombs, Maxwell E., and Donald L. Shaw. "The Agenda-Setting Function of Mass Media." Public Opinion Quarterly, vol. 36, no. 2, 1972, p. 176., doi:10.1086/267990.

[13] Guo, Qingguang. Chuan Bo Xue Jiao Cheng. Zhong Guo Ren Min Da Xue Chu Ban She, 2011.

[14] "On the Relation of Analytical Psychology to Poetry." Collected Works of C.G. Jung, Volume 15: Spirit in Man, Art, And Literature, 2014, pp. 65-83., doi:10.1515/9781400850884.65.

[15] Mufson, Steven. "CHINA'S LEAP BACKWARD." The Washington Post, WP Company, December 6 1994 ,

www.washingtonpost.com/archive/sports/1994/12/ 06/chinas-leap-backward/13f2284e-f30b-4225-ab9 1-5a784d5deb9f/.

[16] "China Demands Apology for Australian Swimming' Drug Cheat' Slur." BBC News, BBC, 8 Aug. 2016 , www.bbc.com/news/world-australia-37006687.

[17] Booker, Brakkton. "Champion Chinese Swimmer Sun Yang Gets 8-Year Ban For Doping Violation." NPR, NPR, $28 \quad$ Feb. 2020 , www.npr.org/2020/02/28/810331548/champion-chin ese-swimmer-sun-yang-gets-8-year-ban-for-doping.

[18] Panja, Tariq. "Sun Yang's Doping Ban Lifted after Accusation of Racism." The Sydney Morning Herald, The Sydney Morning Herald, December 24 2020 , www.smh.com.au/sport/sun-yang-s-doping-ban-lif ted-after-accusation-of-racism-20201224-p56pzm. html.

[19] "Sun Yang, 28, has already attracted the world's attention, but has been dragged down by his own mother. A long apology will not help." Sun bin, 28, has attracted worldwide attention, but by the mother visibly, long apology also of no help || sun Yang | mother _ sina news, March 4. 2021, k.sina.com.cn/article_7037034322_1a3709f520010 Ovawt.html.

[20] "Sun Yang: Eight-Year Ban for Chinese Olympic Champion." BBC Sport, BBC, www.bbc.com/sport/swimming/51670931.

[21] 17 years into his career, how did Sun Yang suffer a heart attack? new.qq.com/omn/20210407/20210407A08HKX00 .html.

[22] John, Tara. "Olympic: China Mocks Australia After Mack Horton Doping Jibe." Time, Time, 8 Aug. 2016 , time.com/4442987/china-daily-mach-horton-austra lia-sun-yang-drug-cheat/.

[23] ABC News. "Swiss Court Says Judge's Anti-China Bias Is Reason for Sun Yang Getting a Retrial." ABC News, ABC News, 15 Jan. 2021, www.abc.net.au/news/2021-01-15/judge-in-sun-ya ng-doping-cas-case-had-doubtful-impartiality/1306 3050 .

[24] Potter, W. James (2010-11-30). "The State of Media Literacy". Journal of Broadcasting \& Electronic Media. 54(4): 675 696. doi:10.1080/08838151.2011.521462. ISSN 08 83-8151. S2CID 143563044.

[25] Ming-yuan gu. Education Dictionary: Shanghai Education Press, 1998. 